\title{
A PRECISE NARROW-BEAM FUTER INFRARED RADIOMETER AND ITS USE WITH LIDAR IN THE ARM PROGRAM
}

DOE/ER/61373-..1

DE92 016872

\section{PROGRESS REPORT}

for period 1 December, 1391 - 31 May, 1992

C.M.R. Platt

CSIRO, Division of Atmospheric Research

Private Mail Bag No.1

Mordialloc Victoria Australia $\mathbf{2 1 9 5}$

May 1992

Prepared for

THDE US DEPARTMENT OF ENERGY AGREEMENT NC. DE-FG02-82ER01834 
NOTICE

This report was prepared as an account of work sponsored by the United States Government. Neither the United States nor the Department of Energy, nor any of their employees, nor any of their contractors, subcontractors, or their employees, makes any warranty, express or 1mplied, or assumes any legal liability or responsibility for the accuracy, completeness, or usefulness of any information, apparatus, product or process disclosed or represents that its use would not infringe privately-owned rights. 


\section{ABSTRACT}

The first six months of the grant have been taken up with the design and specification for the new narrow-beam radiometer. The radiometer will be built and tested at the Division of Atmospheric Research over the next three months. Improved algorithms for obtaining cloud extinction have also been developed.

It is proposed during 1993 to use the radiometer in conjunction with a new CSIRO 3-wavelength lidar in the ARM PROBE experiment at Kavieng, New Guinea, which is a test mission under tropical conditions for the ARM CART Tropical West Pacific site, and is part of the TOGA COARE experiment. During the latter part of 1992, the radiometer will be tested thoroughly and tested at the Division of Atmospheric Research, Aspendale.

\section{PROGRESS AND FURTHER WORK}

The narrow-beam filter radiometer proposed in 1991 has reached an advanced stage of design. It is anticipated that fabrication will be completed ready for testing by October 1992. Much of the wor $\mathrm{k}$ will be carried out in the Division alihough some will be contracted. There is then the opportunity to test the radiometer performance in the ARM PROBE field study in January 1993 associated with TOGA COARE in Kavieng, New Ireland, Papua New Guinea, to the north of Australia, in a study of tropical clouds. In that experiment the radiometer will be used in conjunction with the Division's new lidar in the Australian Lidar/Radiometer (IIRAD) method. It is proposed to introduce the LIRAD method as an analysis technique for the ARM program.

During the first six months, the Principal Investigator has spent about one month equivalent time on the project. This amount is expected to increase as the radiometer nears completion and requires calibration. The Engineer on the project Mr J W Bennett, has spent a similar amount of time, which constitutes the CSIRO salary contribution for this period. The PI and colleagues have also developed methods to recover cloud extinction above cloud base.

During the subsequent six month's period to PROBE, the performance of the radiometer will be thoroughly examined using the data obtained from PROBE, and LIRAD parameters for tropical clouds will be deduced.

There are then two possible courses of action, according to the ARM requirements:

* First, the radiometer could be further tested under field conditions at the firs: ARM CART site in Oklahoma, during the northern summer, 1993. This would enable a good assessment of the instrument under ARM CART conditions. 
* Second, the radiometer could be first modified to include a Stirling cycle refrigerator cooler for the infrared Mercury Cadmium Telluride detector. This cooler would keep the detector at the required temperature of liquid nitrogen without the need for repetitive filling of a liquid nitrogen dewar. Such a requirement would seem desirable, if not essential, for CART site operation.

It could be beneficial to install the Stirling cycle cooler before using the radiometer at the Oklahoma CART site and this is probably the course which will be taken. On the other hand, it might be better to test the radiometer out as a suitable instrument first. Input from the ARM Science team will be sought during the next year, particularly at the next ARM science team meeting.

Whichever course of action is finally decided on, the radiometer will be fieldtested thoroughly during the next 12 months.

An aspect not yet mentioned is that a scientist in the ARM program has requested a duplicate of the radiometer for his own use. This will probably also be fabricated at the Division of Atmospheric Research, at cost price. The implications for the ARM program need to be explored.

Finally, it is proposed to carry out some work during 1993 on the novel technique suggested in the 1991 proposal of incorporating a passive filter radiometer within the same optical system as a lidar, both to exploit the large lidar mirror aperture and the coaxial nature of the two instruments.

The design for the new filter radiometer is discussed in section 3. Plans for further work are given in detall in the following document.

\section{DESIGIN FOR THE PRECISE NARROW-BEAM FILTER RADIOMETER}

The design of the radiometer has now been completed. It is essentially similar to the original LIRAD radiometer, but with some detailed modifications:

(i) A Mercury Cadmium Telluride ( $\mathrm{Hg} \mathrm{Cd} \mathrm{Te)} \mathrm{detector} \mathrm{is} \mathrm{employed} \mathrm{to} \mathrm{replace}$ the original Golay pneumatic detector.

(ii) The optical design has been modified to present two options; One of two alternative designs will be used for the reference blackbody, normally maintained at $40^{\circ} \mathrm{C}$, and associated chopper:

(a) The original direct aperture chopper as used in the CSIRO LIRAD radiometer, and as presented in the original proposal. 
(b) A $45^{\circ}$ reflection chopper which will lead the signal from an offset blackbody into the main beam.

(iii) The HgCdTe detector requires the signal to be chopped at least at $100 \mathrm{~Hz}$ to enable the synchronously detected system noise to be suffictently low. Thus, either of the choppers clescribed in (ii) above will be required to rotate at speed. With the current availability of small, fast electric motors, it is considered that the required frequency is attainable with either design (a) or (b) above. At present, we are leaning towards option (a) because of the proven stability of the design.

(iv) The ray path from the field aperture to the detector will be entirely reflecting, apart from the narrow-band filter which determines the spectral bandwidth, and will employ off-axis parabolic reflectors. This design will simplify the detector foreoptics considerably.

Schematics of the optical system are illustrated in Figures 1 and 2.

Figure 1 shows the optical system from the input chopper to the detector. In this case the first method ((ii)(a) above) is illustrated. The (parallel) rays, after reflection by the primary and secondary mirrors, are brought to a focus at the field aperture. They are then collimated, passed through the interference filter, and subsequently focussed on the $\mathrm{Hg} \mathrm{Cd}$ Te detector element, which is $1.5 \mathrm{x}$ $1.5 \mathrm{~mm}$ square.

Figure 2 shows the alternative method ((ii)(b)) of chopping the radiation.

The radiometer will be mounted on a portable frame which also includes a rotating reflecting mirror which reflects either the required signal radiance, or radiance from the cold blackbody, onts the radiometer entrance aperture. The input $45^{\circ}$ mirror also allows scanning of the sky in two dimensions to obtain cloud or clear-sky radiance at various zenith angles.

\section{Minimum detectable signal}

As stated in the original proposal, the present Mark2 CSIRO radiometer does not have sufficient sensitivity to detect the weakest signals from the typical low density tropical cirrus.

Following the notation in the original proposal, the minimum detectable radiance $L_{R}$ is given by (Eq. 33 of proposal) 


$$
\begin{gathered}
\mathrm{L}_{\mathrm{B}}=\xi \mathrm{A} \delta \mathrm{W} \mathrm{L}_{\mathrm{R}} \\
\text { or } \mathrm{L}_{\mathrm{R}}=\mathrm{L}_{\mathrm{E}} / \xi \mathrm{A} \delta \mathrm{W}
\end{gathered}
$$

where $L_{\mathrm{E}}$ is the detector notse equivalent power, (NEP), $\xi$ is an instrumental loss factor, and $\mathrm{A}$ and $\delta \mathrm{w}$ are the radiometer aperture and field of view respectively.

The proposed new radiometer has a characteristic NEP of $L_{\mathbb{E}}$ equal to $2 \times 10^{-12}$ $\mathrm{W}(\mathrm{hz}) .^{-t_{\mathrm{s}}}$ The radiances at the ground for a cirrus cloud of emittance $\varepsilon_{\mathrm{a}}=0.1$ and atmospheric transmittance of 0.5 are shown in Table 1 , for time constants of both 1 second and 10 seconds. We take $A=4 \mathrm{~cm}^{2}$ and $\delta \mathrm{w}=2.83 \times 10^{-5} \mathrm{sr}$ ( 0.3 degrees FOV).

TABLE 1

High-Cloud $\left(\varepsilon_{\mathrm{a}}=0.1\right)$ radiances $\left(L_{\mathrm{s}}\right)$ at the ground

\begin{tabular}{|c|c|c|c|}
\hline Cloud Temp. & $L_{\mathrm{s}}$ & $\mathbf{L}_{\mathrm{R}}(\mathbf{1})$ & $\mathbf{L}_{\mathrm{R}}(\mathbf{1 0})$ \\
\hline$\left.{ }^{\circ} \mathrm{C}\right)$ & \multicolumn{3}{|c|}{$\left(\mathrm{Wcm}^{-2} \mathbf{S r}^{-1}\right)$} \\
\hline-70 & $2.8 \times 10^{-7}$ & $1 \times 10^{-7}$ & $3.2 \times 10^{-8}$ \\
\hline \multicolumn{3}{|c|}{$1 \times 10^{-7}$} & $3.2 \times 10^{-8}$ \\
\hline-60 & $4.0 \times 10^{-7}$ & & $3.2 \times 10^{-8}$ \\
\hline & & $1 \times 10^{-7}$ & $3.5 \times 10^{-7}$ \\
\hline
\end{tabular}

In the LIRAD mode, including the ECLIPS experiment, the lidar takes observations at every 30 second interval. Thus, a time constant of 10 seconds (last column) is permitted. It can be seen that thin cirrus cloud gives a signal to noise ratio of at least 10 in that case.

\section{Filers}

The aim is to have three narrow-band filters at centre wavelengths of approximately $8 \mu \mathrm{m}, 10.8 \mu \mathrm{m}$ and $12 \mu \mathrm{m}$ and bandwidths of $1 \mu \mathrm{m}$. This range of wavelengths will help to delineate the varlability in cirrus emittance, and will also give information on the water vapour absorption coefficient. This is dominated by the water vapour continuum in tropical atmospheres. 


\section{Algorithm for Extinction}

An algorithm for cloud extinction above base for the case of optically thick clouais has been developed. This algorithm has been used for boundary layer clouds in the Experimental Cloud Lidar Pilot Study (ECLIPS), and gives useful information on how cloud extinction varies above cloud base, a relation which depends on cloud formation and condensation nuclei available. The IR radiometer is vital to gauge when the emittance of the cloud is approaching unity. A comparison of data from tropical clouds with those obtained from mid-latitude cases will be extremely useful. 

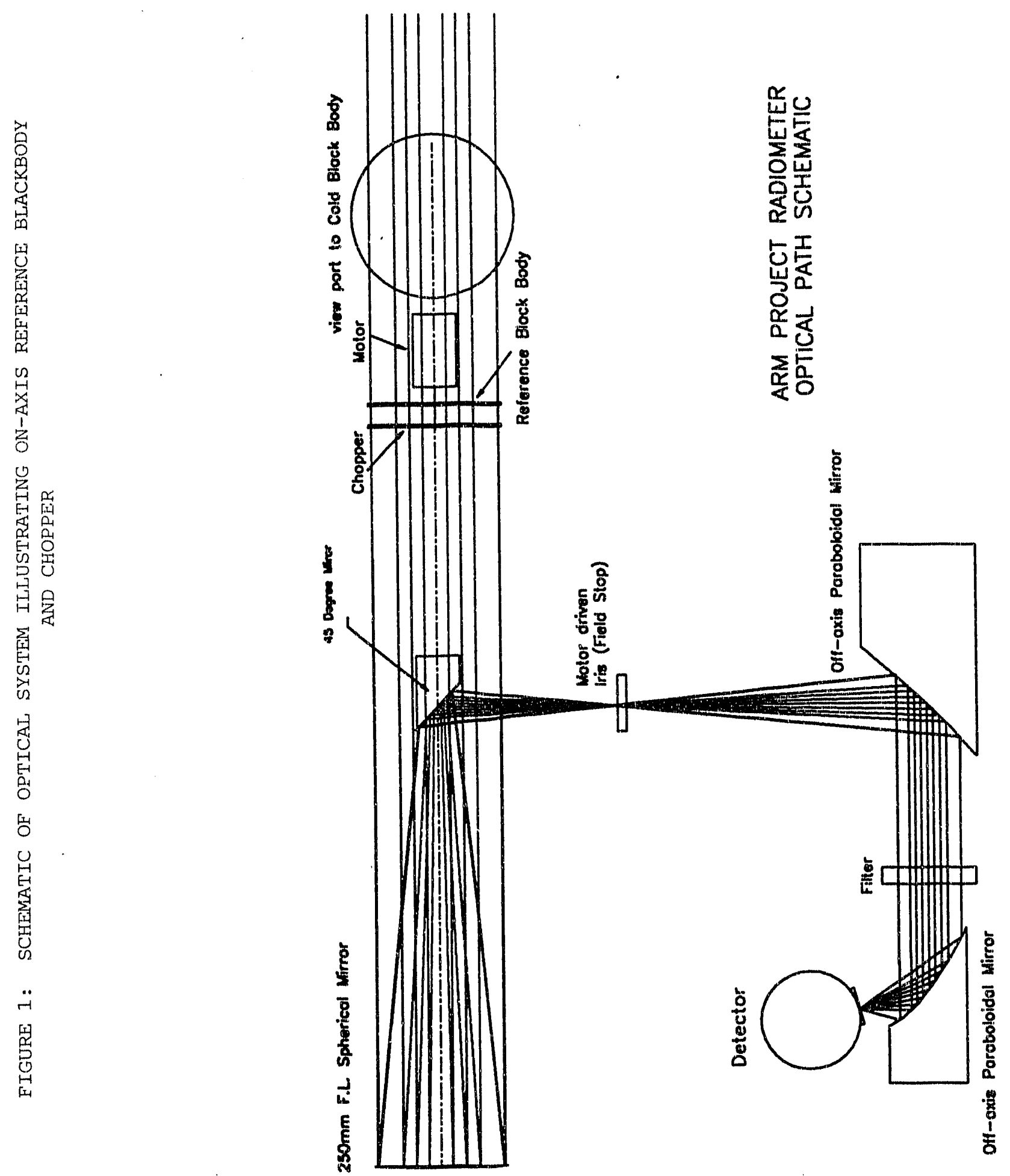
FIGURE 2: ALTERNATIVE CHOPPING MECHANISM AT OPTICAL INPUT

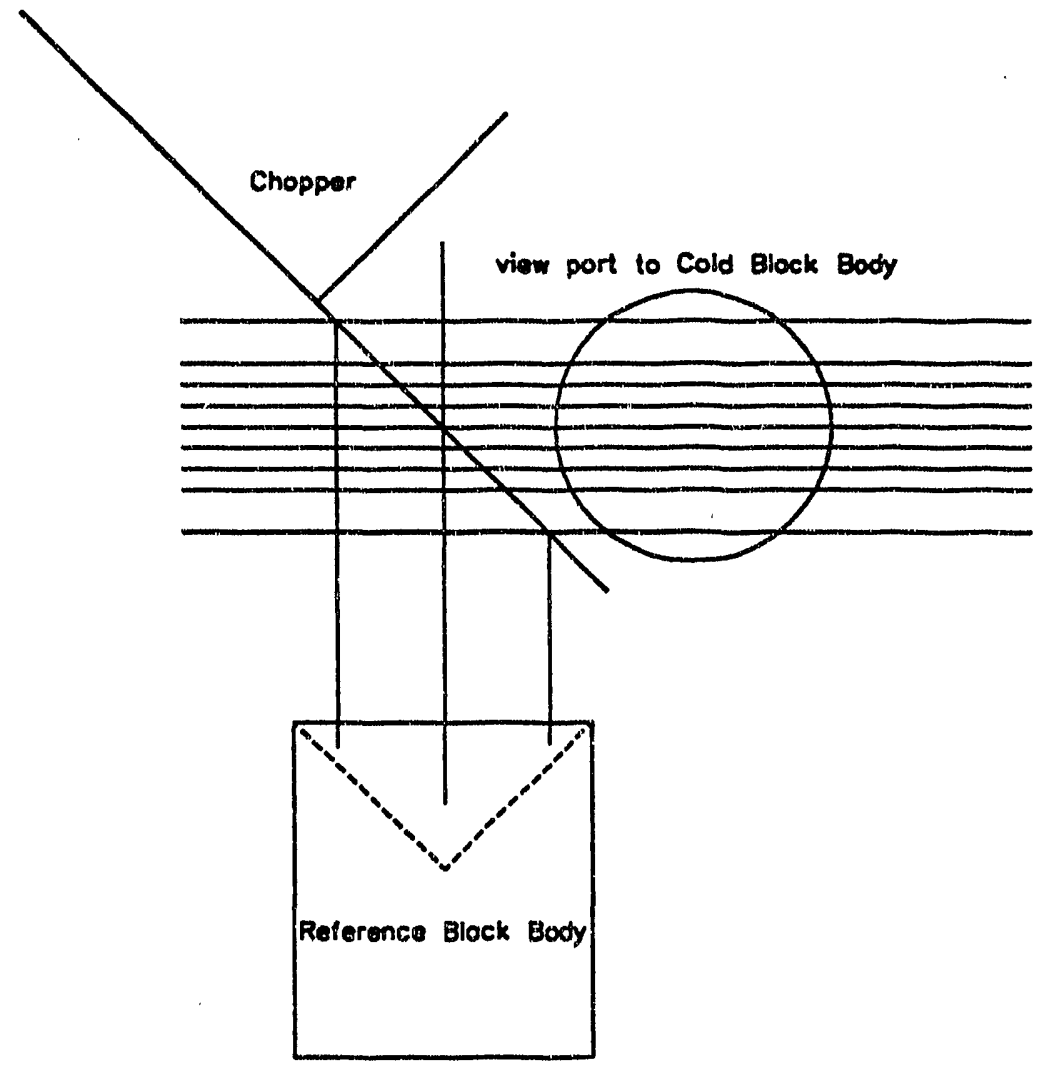



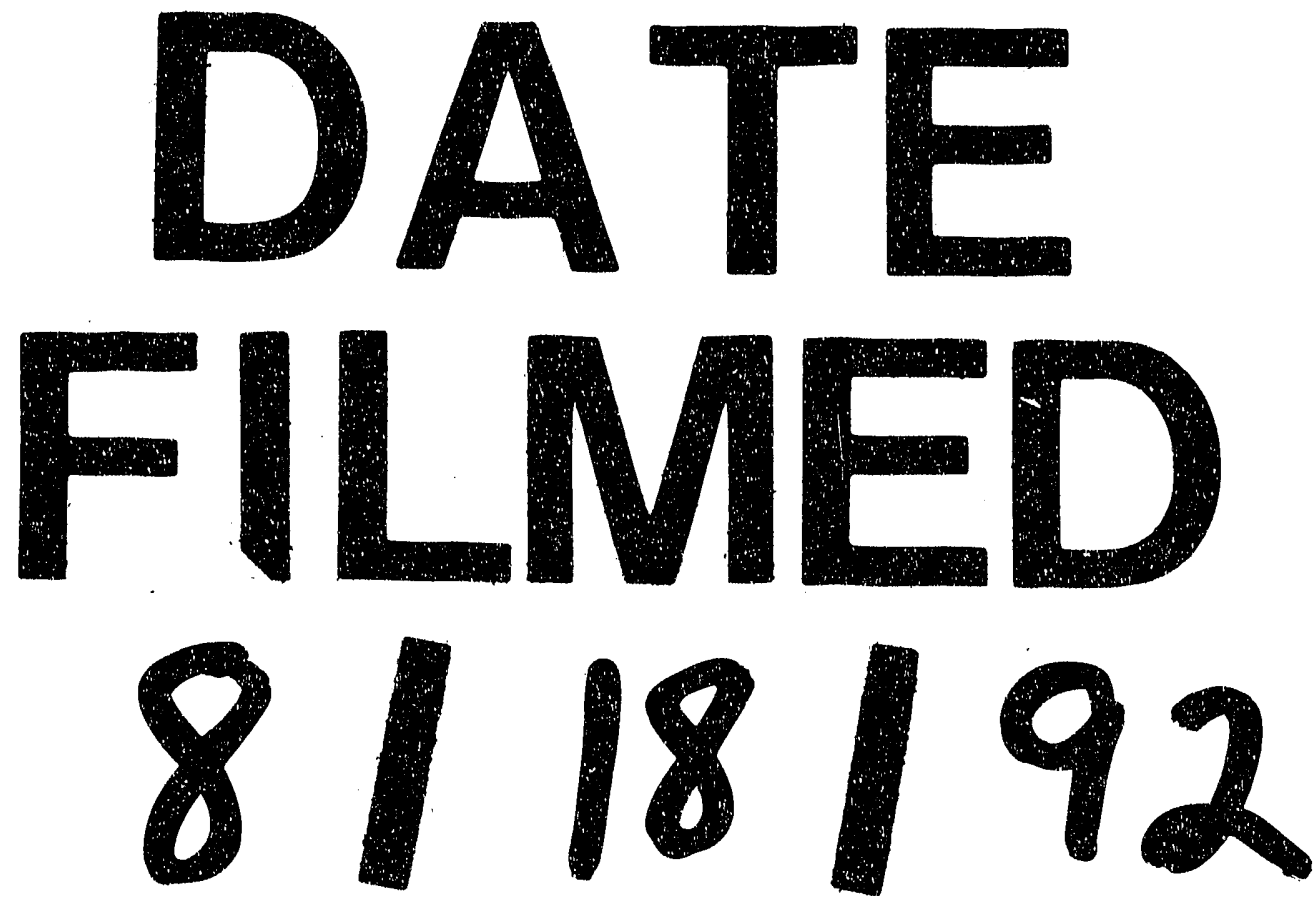
